\title{
Can Targeting Iron Help in Combating Chronic Pseudomonas Infection? A Systematic Review
}

\author{
Amena Firoz ${ }^{1}$, Muhammad Haris ${ }^{2}$, Khadija Hussain ${ }^{3}$, Maham Raza ${ }^{2}$, Deepak Verma ${ }^{2}$, Manel Bouchama \\ ${ }^{2}$, Karez S. Namiq ${ }^{4}$, Safeera Khan ${ }^{2}$ \\ 1. Pediatrics, California Institute of Behavioral Neurosciences \& Psychology, Fairfield, USA 2. Internal Medicine, \\ California Institute of Behavioral Neurosciences \& Psychology, Fairfield, USA 3. Radiology, California Institute of \\ Behavioral Neurosciences \& Psychology, Fairfield, USA 4. Oncology, California Institute of Behavioral Neurosciences \\ \& Psychology, Fairfield, USA
}

Corresponding author: Amena Firoz, amenafiroz02@gmail.com

\begin{abstract}
Cystic fibrosis is an autosomal recessive disorder caused by a mutation in genes for cystic fibrosis transmembrane conductance regulator (CFTR) protein. CFTR gene is responsible for the production of sweat, digestive fluids, and mucus, and any mutation in this would lead to the thickening of these secretions. Cystic fibrosis is a multi-organ disorder, but $80 \%$ of patients suffer from respiratory problems due to chronic infections most commonly caused by Pseudomonas aeruginosa (P. aeruginosa). Eradication of these infections has become a challenge as $P$. aeruginosa has developed resistance to multiple antibiotics. In several studies, iron has been shown to play an integral role in biofilm formation, which is the predominant resistance mechanism used by $P$. aeruginos $a$ to combat antibiotics. The increased iron content in cystic fibrosis patients' sputum samples explains their increased susceptibility to Pseudomonas infections. Hence in this review article, we have used the research data available on therapeutic agents that target iron as an adjuvant treatment for chronic Pseudomonas infection. We systematically screened three databases using focused words and Medical Subject Headings (MeSH) terms for relevant articles. Further, we applied the inclusion and exclusion criteria and performed a thorough quality appraisal. Thirty shortlisted relevant studies were meticulously reviewed. In our opinion, novel therapeutic approaches targeting iron such as iron chelators, gallium, and cefiderocol have potent anti-biofilm properties. Future studies and clinical trials using these approaches in the management of chronic Pseudomonas infection might help in decreasing morbidity and mortality in patients with cystic fibrosis. Exploring these approaches might also help to combat other resistant organisms whose survival is dependent on iron.
\end{abstract}

Received 02/12/2021 Review began 02/22/2021 Review ended 02/23/2021 Published 03/05/2021

() Copyright 2021 Firoz et al. This is an open access article distributed under the terms of the Creative Commons Attribution License CC-BY 4.0., which permits unrestricted use, distribution, and reproduction in any medium, provided the original author and source are credited.
Categories: Genetics, Internal Medicine, Pediatrics

Keywords: iron metabolism, iron, pseudomonas infections, siderophores, gallium, iron chelators, iron uptake, cystic fibrosis, biofilm formation, cefiderocol

\section{Introduction And Background}

Cystic fibrosis, first described by Dr. Dorothy Andersen in 1938, has become the most common life-limiting recessive genetic disorder in Caucasians [1]. Approximately 70,000 people live with cystic fibrosis worldwide (more than 30,000 in the USA) [1,2]. One thousand new cases are diagnosed each year, with males and females affected in equal numbers, and more than $75 \%$ are diagnosed at two years of age $[1,2]$.

Cystic fibrosis is caused by mutations in the cystic fibrosis transmembrane conductance regulator (CFTR) gene, located on chromosome 7 (7q31.2) [1]. This gene is fundamentally expressed in the airways' epithelium, intestinal tract, pancreas, and sweat glands. It is responsible for regulating the transfer of chloride and sodium across cell membranes, and hence its mutation leads to the thickening of the mucus and other secretions [3].

Cystic fibrosis affects multiple organ systems, especially the lungs and pancreas, but intestines, liver, sweat glands, and reproductive organs also are frequently affected [1]. Approximately $80-95 \%$ of patients with cystic fibrosis give in to respiratory failure caused by chronic bacterial infection [4]. One of the detrimental opportunistic pathogens that colonize the adult cystic fibrosis lung is Pseudomonas aeruginosa ( $P$. aeruginosa) [5]. According to the Cystic fibrosis Foundation Registry Annual Report 2018, 45.3\% of cystic fibrosis patients in the US were recorded to have P. aeruginosa cultured from their sputum, and $16.9 \%$ of them were positive for multidrug-resistant $P$. aeruginosa [2].

P. aeruginosa combats antibiotic attack with either intrinsic, acquired, or adaptive resistance [6], adaptive resistance being the most pertinent to our review article. It involves biofilm formation, a structured aggregate of bacteria implanted in a self-produced matrix consisting of polysaccharide, protein, and DNA [7]. Biofilms help to endure unpredictable changes in temperature fluctuation and nutrient availability and also serve as a diffusion-barrier to limit antibiotic access to the bacterial cells [8-9]. Figure 1 below illustrates the distinctive time course of $P$. aeruginosa colonization of the cystic fibrosis respiratory tract and resistance 


\section{Cureus}

mechanisms.

Phases of $P$. aeruginosa infection in CF

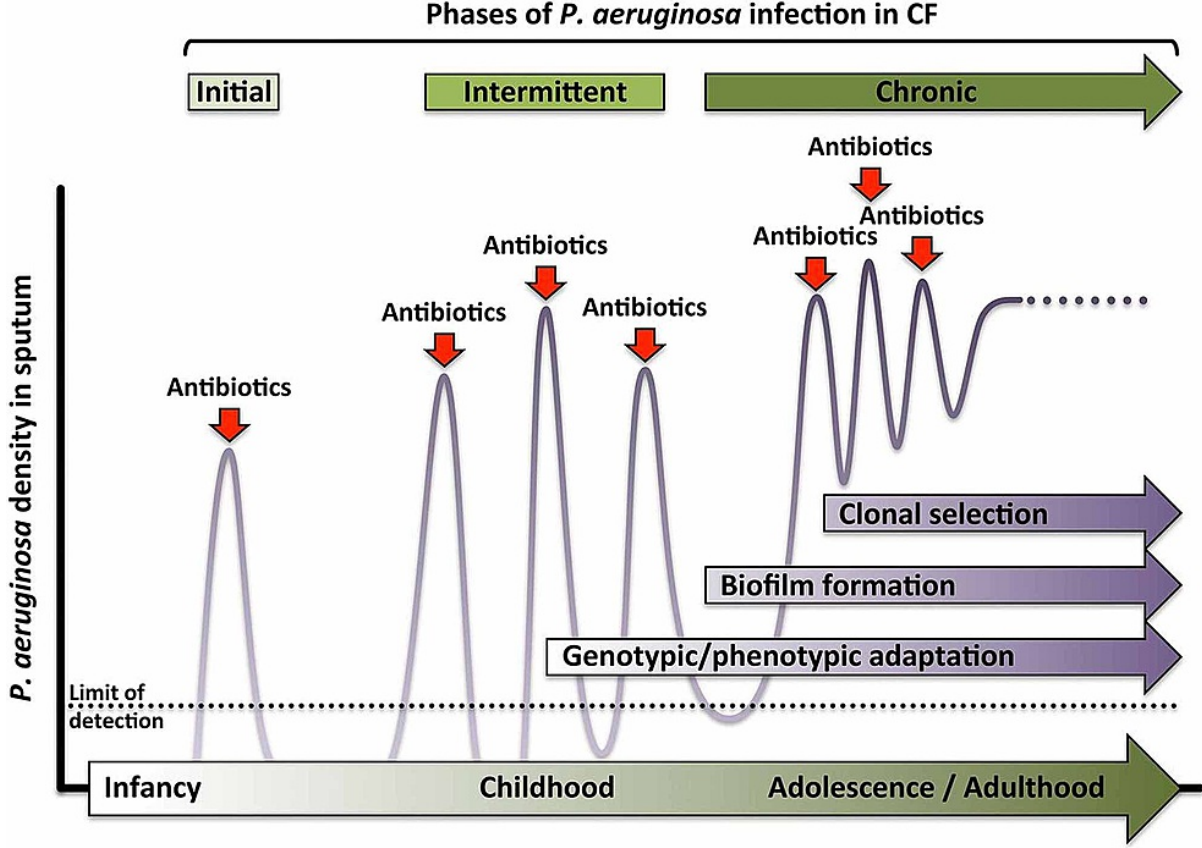

\section{FIGURE 1: Timeline of Pseudomonas aeruginosa colonization in cystic fibrosis}

Initial infection with Pseudomonas aeruginosa is eradicated with antibiotics. Subsequent intermittent infections cause impairment in bacterial clearance due to genetic adaptation of the bacteria to cystic fibrosis airways. The adaptations form biofilms, production of mucoid coating, and altered expression of virulence factors, leading to chronic infections

Reprinted with permission from Nicole M. Bouvier [10]

Acute Pseudomonas Infections can be eradicated if treated early, but successful therapy is currently unavailable to eliminate a chronic $P$. aeruginosa infection due to the rise of antibiotic resistance. The development of new antibiotics is a laborious process; hence antibiotic adjuvants, agents that act along with a concurrently administered antibiotic, enhancing its action, may offer a novel therapeutic approach to treat antibiotic-resistant Pseudomonas infections [11]. One of the targets for therapy currently being investigated is iron, as it has been a critical factor in biofilm formation in P. aeruginosa [12]. Regulating microorganismal survival by limiting iron availability may be achieved using agents that target iron uptake pathways and/or iron chelators [13].

While the recommendation of interrupting bacterial nutrition as an antimicrobial strategy was put forward by Louis Pasteur in the 1800s, therapeutic strategies targeting vital bacterial nutrients have been difficult to develop $[14,15]$. Hence, this systematic review aims to learn about iron metabolism in cystic fibrosis patients, iron uptake mechanisms of $P$. aeruginosa, and new strategies targeting iron to help subdue chronic Pseudomonas infections in cystic fibrosis patients.

\section{Review}

\section{Methods}

We conducted a systematic review following Preferred Reporting Items for Systematic Reviews and MetaAnalyses (PRISMA) guidelines [16].

Data Source and Strategy

We searched for articles indexed in PubMed, PMC, MEDLINE (National Library of Medicine), and Google Scholar (Alphabet Inc., Mountain View, CA) from December 28 to December 30, 2020. We applied keywords and Medical Subject Headings (MeSH) terms individually and in combination to identify relevant articles. Also, articles referenced in those identified in this search were reviewed for relevance. At the end of our search, we eliminated duplicate articles. Table 1 and Table 2 summarize the search strategy using MeSH terms and keywords. 


\section{Cureus}

\section{MeSH strategy}

("Iron Chelating Agents" [Pharmacological Action]) AND "Pseudomonas Infections/therapy"[Mesh]

("Pseudomonas Infections/therapy"[Mesh]) AND "Biofilms/growth and development"[Mesh]

("Biofilms/growth and development"[Mesh]) AND "Iron/metabolism"[Mesh]

("Iron/metabolism"[Mesh]) AND "Cystic Fibrosis/therapy"[Mesh]

("Cystic Fibrosis/etiology"[Mesh]) AND "Pseudomonas Infections/physiopathology"[Mesh]

("Iron Chelating Agents/therapeutic use"[Mesh]) AND "Cystic Fibrosis/therapy"[Mesh]

("Pseudomonas Infections/etiology"[Mesh]) AND "Biofilms/growth and development"[Mesh]

("Pseudomonas Infections/mortality"[Mesh]) AND "Cystic Fibrosis/microbiology"[Mesh]

\section{TABLE 1: Search strategy with MeSH terms}

MeSH: Medical Subject Headings

\section{Keywords in combination}

iron metabolism in cystic fibrosis

Pseudomonas infection and iron uptake

iron chelators in cystic fibrosis

Pseudomonas biofilm formation and iron

Siderophores in Pseudomonas infection

iron chelators in Pseudomonas infection

\section{Search results}

307

108

103

259

353

195

\section{TABLE 2: Search strategy with keywords}

Study Selection and Eligibility Criteria

Once we identified the relevant articles, we screened their titles and read through the available abstract and full text of pertinent studies. We included peer-reviewed articles that were published in the English language in the last 15 years. We focused on chronic Pseudomonas infection without any age or gender discrimination. The entire review was done scientifically and within ethical boundaries.

Risk of Bias Assessment

The quality of included studies was assessed by the following tools:

a) Newcastle-Ottawa checklist - observational/non-randomized controlled trial

b) Scale for the Assessment of Narrative Review Articles (SANRA) checklist - traditional review articles

c) Joanna Briggs Institute (JBI) checklist - case reports/case series

Only those articles that satisfied $>70 \%$ of the checklist quality parameters were included in the review.

\section{Results}

Study Identification and Selection Results

We used four databases to collect relevant articles: PubMed, PMC, MEDLINE, and Google Scholar. Our initial 
search yielded 2,489 articles: 1,325 identified with keywords, and 1,164 using the MeSH Strategy. After the duplicates were removed $(n=1,275), 1,214$ articles were screened by title for relevance, following which 985 non-relevant articles were excluded. Abstracts and full text of the 256 relevant articles that remained were thoroughly read, and 223 of them were excluded after inclusion criteria were applied. Lastly, after meticulous quality assessment, three articles were further excluded, and finally, 30 articles were included in the review. Figure 2 depicts the search process in the form of a PRISMA flow diagram.

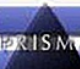

PRISMA 2009 Flow Diagram

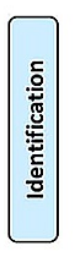

Records identified through PUBMED, PMC, MEDLINE and Google Scholar using

$$
\text { Keywords }
$$
$(n=1325)$

Records identified through PUBMED with MeSH Strategy

$(n=1164)$

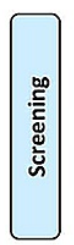

Total Records $(n=2489)$

Records after duplicates removed

( $n=1214$ )
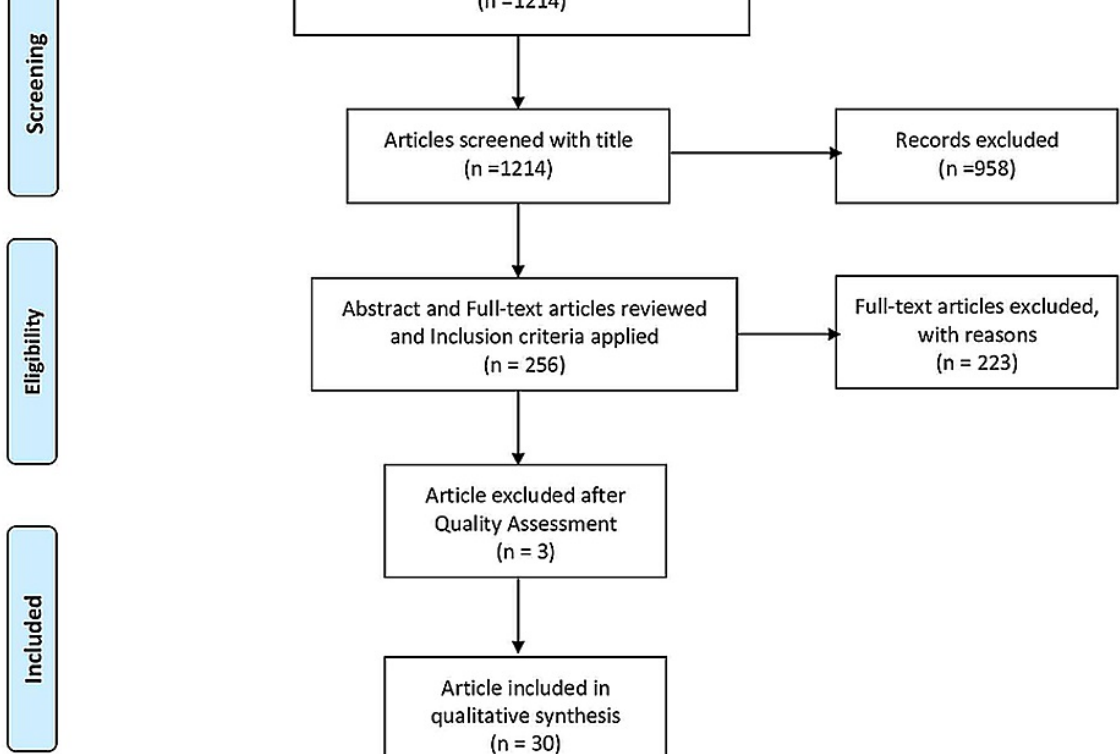

\section{Article excluded afte \\ Quality Assessment} $(n=3)$

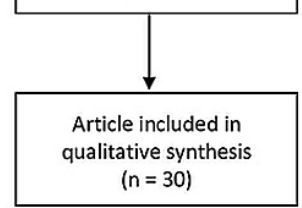
From: Moher D, Liberati A, Tetzlaff J, Altman DG, The PRISMA Group (2009). Preferred Reporting ftems for Systematic Reviews and Meta-

For more information, visit www.prisma-statement.org.

\section{FIGURE 2: PRISMA flow diagram outlining the search process}

PRISMA: Preferred Reporting Items for Systematic Reviews and Meta-Analyses

\section{Quality Assessment}

We carried out a rigorous quality assessment for the 33 finalized articles by using various tools like the Newcastle-Ottawa checklist $(n=3)$, the SANRA checklist $(n=16)$, and the JBI checklist $(n=12)$. Two articles were excluded due to unavailable full-text articles for assessment and one article was excluded as it did not satisfy our cut-off (>70\%). Therefore, we were finally left with 30 articles to include in our review.

\section{Study Characteristics}

The finalized articles were all peer-reviewed articles published in the last 15 years with full texts freely available. All articles were in English, and articles in other languages were excluded due to unavailable English translations. Human and in vitro studies were included. The condition investigated was Chronic Pseudomonas infection. Hence, cystic fibrosis subjects with chronic infection or cells from cystic fibrosis 
patients' airways or different strains of $P$. aeruginosa were studied in reviewed articles; $50 \%$ of the reviewed articles were traditional reviews, and the remaining $50 \%$ included observational studies, in vitro studies, and a few case series.

\section{Discussion}

We studied 30 previously published articles to understand the importance of iron in chronic Pseudomonas infections, mainly concerning cystic fibrosis patients, in order to gain an updated understanding of the novel therapeutics developed against the same.

Iron Metabolism in Cystic Fibrosis Patients

The normal airway is usually iron-depleted, whereas, in cystic fibrosis, tissue damage due to chronic inflammation and infection increases the airway's iron content [12]. A study conducted by Moreau-Marquis et al. showed that the expression of the most common mutation of CFTR- $\Delta$ F508-CFTR mutation in airway cells increases iron release, which enhances biofilm formation, thereby increasing resistance of $P$. aeruginosa to tobramycin $(\mathrm{Tb})$; therefore, the amount of $\mathrm{Tb}$ required to eliminate $P$. aeruginosa biofilms on airway cells is 10 times more than the amount achievable in the lungs of cystic fibrosis patients [12].

A similar study conducted by Reid et al. showed that increased sputum iron content in stable cystic fibrosis patients had a direct relationship with $P$. aeruginosa quantitative load, which indicates that iron is a vital factor in its growth and survival [17]. Also, some patients with cystic fibrosis who had no detectable $P$. aeruginosa presence had increased sputum iron and ferritin levels than normal controls, implying increased iron may be an early event that precedes $P$. aeruginosa infection [17]. Apart from enhancing the growth of $P$. aeruginosa in cystic fibrosis patients, elevated iron levels also hamper the host's innate immune system by impairing neutrophil function and rapidly saturating the binding capacities of lactoferrin and transferrin, thereby neutralizing their antimicrobial effects [18-20].

Iron Uptake Pathways by Pseudomonas Aeruginosa

Iron is essential for almost all pathogens; it is also required in numerous vital processes, including DNA synthesis, electron transport, and defense mechanisms [21]. Hence, to cope with iron limitation, bacterial pathogens develop various iron-acquiring pathways that have been described in a study conducted by Cornelis et al., and Figure 3 highlights these pathways [22].

- By production of siderophores (pyoverdine and pyochelin) and the uptake of ferrisiderophores via TonB-dependent receptors (TBDR).

\section{Pathway 1}

- By extracellular reduction of $\mathrm{Fe}^{3+}$ to $\mathrm{Fe}^{2+}$ involving phenazine compounds and the Feo system.

Pathway 2

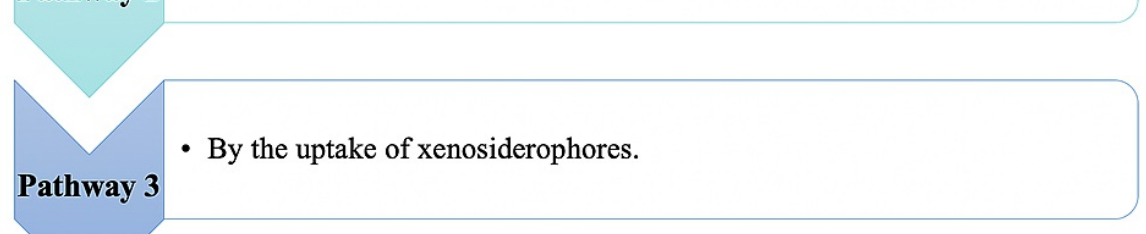

Pathway 3

- By the uptake of xenosiderophores.

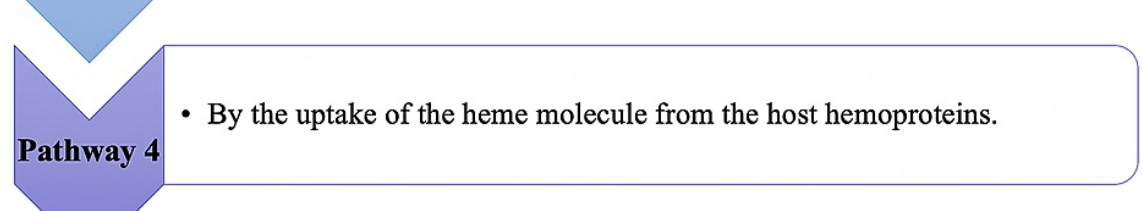

Pathway 4

FIGURE 3: Iron uptake pathways by Pseudomonas aeruginosa

Fe2+: ferrous ion; Fe3+: ferric ion

P. aeruginosa adapts to different pathways depending on the type of infection (acute vs. chronic); Nguyen et 
al., in their study, showed that iron is scavenged during acute infections by siderophore pyoverdine, and during prolonged infection, heme is an important source of iron [23]. Apart from the type of infection, iron concentration in the environment also plays a role in the type of endogenous siderophore used for iron acquisition; for example, Banin et al. in their study, state that siderophore pyoverdine is active at low external iron concentration and pyochelin at higher iron levels as pyoverdine has a stronger affinity for iron [24].

\section{Biofilm Formation - A Survival Mechanism}

Chronic Pseudomonas infections prevail as the bacteria have developed mechanisms to retaliate against antibiotics; Pang et al., in their review, classify these mechanisms into intrinsic, acquired, and adaptive resistance [6]. Intrinsic resistance includes low outer membrane permeability, expression of an efflux pump, and formation of antibiotic-inactivating enzymes [6]. The acquired resistance can be obtained through resistance genes or mutational changes [25]. Lastly, adaptive resistance requires the formation of biofilms that limit antibiotic access to bacteria [7]. Multidrug-tolerant persister cells that form in a biofilm also contribute to recurrent infections. They can withstand an antibiotic attack and regenerate the biofilm once the antibiotic is stopped $[26,27]$.

In 2005, Banin et al. conducted a study in which they described biofilm formation in terms of four important steps: (I) attachment, (II) microcolony formation, (III) maturation of biofilm, and (IV) dispersal, whereas a review article published by Thi et al. in 2020 split the first step into (attachment) initial reversible adhesion and irreversible attachment, thereby making it five steps in biofilm formation [24,9]. Figure 4 is a pictorial representation of the same.

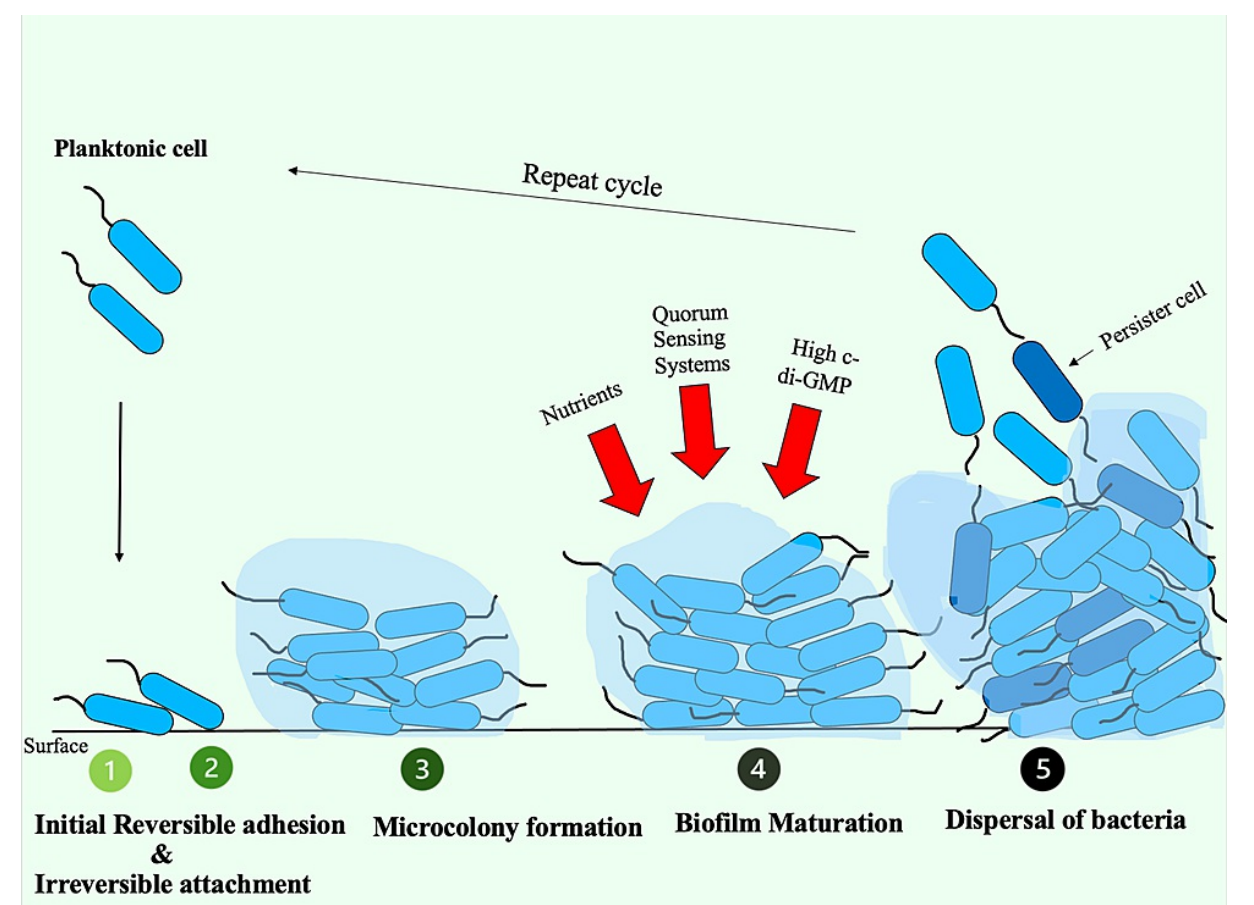

\section{FIGURE 4: Five steps in biofilm formation}

c-di-GMP: cyclic diguanylate

Biofilm formation is a coordinated effort by individual cells to adapt to cell density changes and environmental stress through an interconnected signaling pathway called quorum sensing (QS). There are four clear pathways in the QS circuits of $P$. aeruginosa, namely Las, Rhl, PQS, and IQS, of which PQS is triggered by variation in iron concentration [9]. In their study, Yang et al. presented evidence that during low iron concentration, biofilm development occurs via stimulation of the PQS genes and the formation of extracellular DNA. In contrast, the inverse process occurs during high iron levels [28].

\section{Novel Therapeutics Targeting Iron}

A total of $53 \%$ of children diagnosed with cystic fibrosis through newborn screening developed Pseudomonas infection by five years of age. These chronic pulmonary infections cause a rapid decline in lung function and increase mortality $[29,30]$. It has been speculated that a defect in the CFTR gene may be making patients 
more susceptible to Pseudomonas infections by increasing adherence or reducing clearance of the bacterial cells [31,32]. The innate ability of $P$. aeruginosa to resist antibiotics and have different phenotypic variations has made its eradication challenging. Still, over the last few years, new therapeutics targeting its nutrition and chemical signaling pathways are on the rise. Multiple studies in the past have shown that the availability of cytosolic iron greatly influences biofilm formation. For example, in a study conducted by Soldano et al., blocking the BfrB-Bfd complex, which helps mobilize and reduce ferric ions to ferrous ions, created an iron deprivation state in which bacterial cells poorly developed biofilms despite iron-sufficient culture conditions [33]. Hence the therapeutic strategies we discussed in this review, are iron chelators, gallium, and siderophore-antibiotics, as shown in Figure 5.

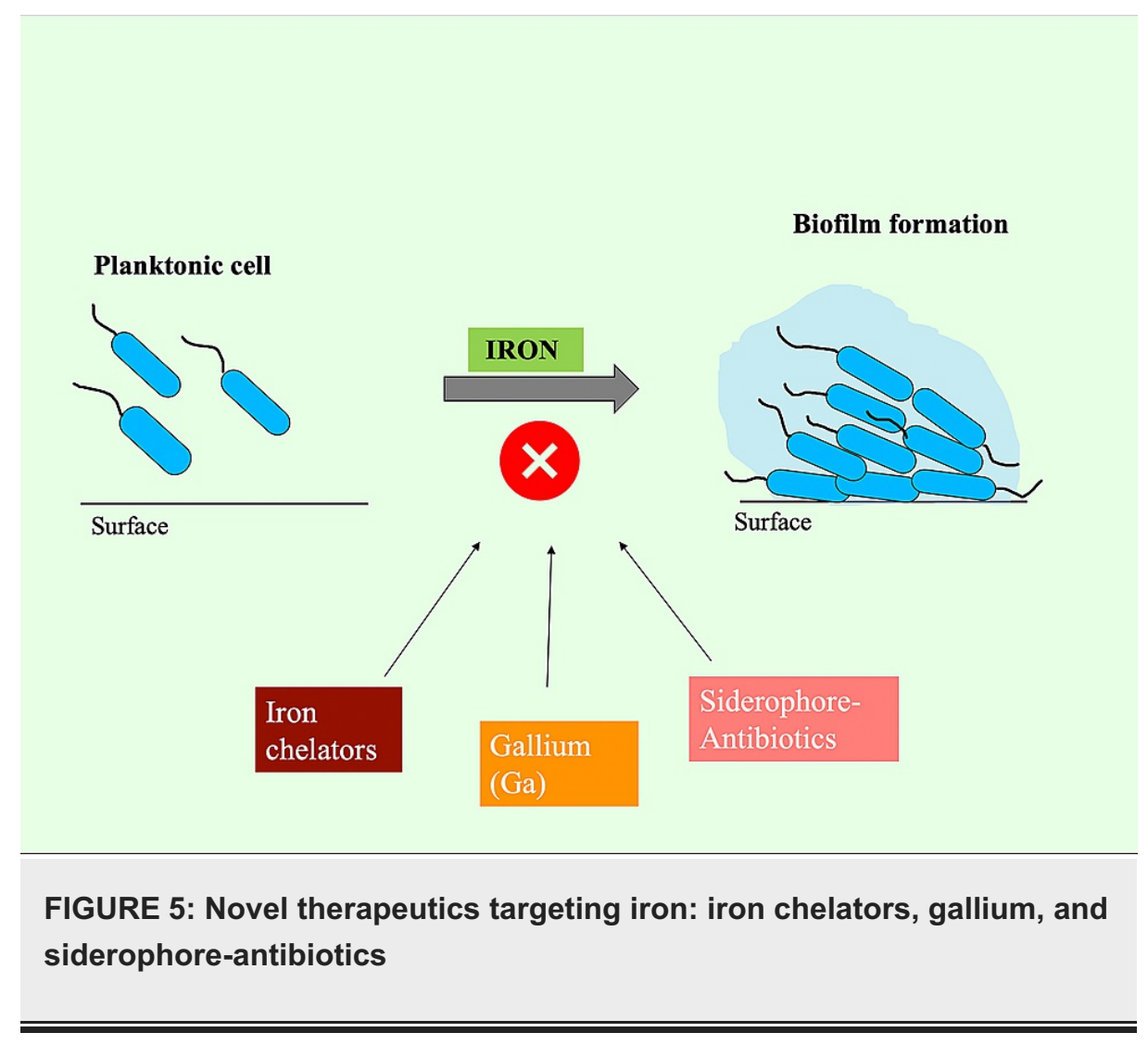

Exogenous iron-chelating agents: our human body can combat any type of invasion through its innate defense mechanism. Lactoferrin is an endogenous iron chelator that at a sub-bactericidal concentration can identify and block biofilm formation by inducing twitching, a type of motility that promotes a planktonic bacterial cell state rather than forming a cluster or biofilm [34]. However, it has been shown that in cystic fibrosis airways, the action of lactoferrin is overpowered by siderophores as they have a stronger affinity toward iron, and also increased proteolysis of lactoferrin impairs its ability to cease biofilm formation $[35,36]$. Taking cues from this defense mechanism, scientists have tried to study the role of exogenous iron chelators like the FDA-approved deferoxamine (DFO) and deferasirox (DSX) in the inhibition of biofilm formation. Several laboratory studies have shown that using iron chelators as an adjuvant to antibiotics has a more preferable anti-biofilm effect than antibiotic use alone. For example, a study conducted by Mettrick et al. has shown that N, N'-bis (2-hydroxybenzyl) ethylenediamine-N, N'-diacetic acid (HBED), a synthetic iron chelator in combination with colistin successfully inhibited biofilm formation in aerobic and anaerobic condition [37]. In a similar study conducted by Moreau-Marquis et al., the combination therapy of tobramycin and iron chelator reduced the formation of biofilms by $90 \%$ [38]. Thi et al., in their review, highlighted cytotoxicity as one of the drawbacks of iron chelator therapy, which is a concern well addressed in a review by Aali et al., which suggests the use of inhalation route of administration, which not only reduces the potential systemic side effects of the iron chelators but also increases the local action of the drug on the lungs $[9,39]$.

Gallium: the use of metal gallium to derange iron metabolism in organisms that thrive on it for various reasons has been contemplated for decades. Gallium has a similar ionic radius as iron, and hence can be easily mistaken for iron by bacterial uptake systems, and its incorporation into iron-containing protein interrupts its function [40,41]. It also has a noticeable effect on iron metabolism whereby it promotes iron starvation by repression of heme/hemoglobin uptake receptor, pyoverdine synthesis, and pyoverdine receptors [42]. Kaneko et al., in their study, show that gallium inhibits P. aeruginosa growth and biofilm formation in vitro by interfering with bacterial uptake and signaling of iron [43]. A similar study conducted by Goss et al. elucidates the important characteristics of gallium that can help impede the growth of $P$. aeruginosa, like inhibiting $P$. aeruginosa ribonucleotide reductase activity, increasing bacterial sensitivity to 
oxidants, and synergistic activity with some antibiotics [15]. We also learn that gallium resistance develops at a slow rate, and unlike lactoferrin, it does not hamper the killing capacity of human macrophages [15]. Gallium is known to be a nephrotoxic drug. Still, when administered as a slow IV infusion to patients who are encouraged to consume two liters of water during the infusion period, on the one hand, it does not affect kidney function, electrolyte levels, and blood counts, and on the other, improves lung function in cystic fibrosis patients [15].

Cefiderocol-siderophore antibiotics: cefiderocol is an injectable siderophore cephalosporin that is structurally similar to third and fourth-generation cephalosporins. Cefiderocol, like other cephalosporins, inhibits cell wall synthesis by binding to penicillin-binding proteins in the cell wall of Gram-negative bacteria [44]. However, its enhanced stability to $\beta$-lactamases and the ability to enter bacterial periplasmic space by utilizing its siderophore-like property make it distinctive [44]. Cefiderocol is considered more potent than ceftazidime-avibactam and meropenem against all resistant forms of $P$. aeruginos $a$; hence, clinical trials are being conducted to get it approved for clinical use [44].

Table 3 summarizes the studies we reviewed from which we learned about these new therapeutic strategies.

\begin{tabular}{|c|c|c|c|c|}
\hline Authors & Year & $\begin{array}{l}\text { Type of } \\
\text { study }\end{array}$ & Purpose or the stuay & Relevant results/conclusion \\
\hline $\begin{array}{l}\text { Thi et al. } \\
\text { [9] }\end{array}$ & 2020 & $\begin{array}{l}\text { Traditional } \\
\text { review }\end{array}$ & $\begin{array}{l}\text { Investigate current diagnostics of } P \text {. } \\
\text { aeruginosa infections and the treatment } \\
\text { of P. aeruginosabiofilms }\end{array}$ & $\begin{array}{l}\text { Iron chelators were discussed as a therapeutic strategy } \\
\text { where bactericidal, biofilm prevention, and low risk of } \\
\text { resistance development stated advantages and } \\
\text { cytotoxicity as limitations }\end{array}$ \\
\hline $\begin{array}{l}\text { Moreau- } \\
\text { Marquis } \\
\text { et al. } \\
\text { [12] }\end{array}$ & 2008 & In vitro study & $\begin{array}{l}\text { Study the antibiotic resistance of } P \text {. } \\
\text { aeruginosa biofilms grown on airway } \\
\text { cells and variation of biofilm formation } \\
\text { on } \Delta \text { F508-CFTR airway cells }\end{array}$ & $\begin{array}{l}\text { The amount of tobramycin required to eliminate } P \text {. } \\
\text { aeruginosa biofilms on airway cells is drastically higher } \\
\text { than the amount present in the lungs of cystic fibrosis } \\
\text { patients. Airway cells expressing } \Delta \text { F508-CFTR increased } \\
P \text {. aeruginosabiofilm formation due to the increased } \\
\text { presence of iron }\end{array}$ \\
\hline $\begin{array}{l}\text { Goss et } \\
\text { al. [15] }\end{array}$ & 2018 & In vitro study & $\begin{array}{l}\text { Understand In-depth about gallium and } \\
\text { conduct a human trial to test its efficacy } \\
\text { in patients with cystic fibrosis }\end{array}$ & $\begin{array}{l}\text { Gallium works by inhibiting ribonucleotide reductase } \\
\text { activity in } P \text {. aeruginosa. Phase lb clinical trial showed } \\
\text { that it improved lung function and was relatively safe } \\
\text { when used in cystic fibrosis patients }\end{array}$ \\
\hline $\begin{array}{l}\text { Reld et } \\
\text { al. [17] }\end{array}$ & 2007 & $\begin{array}{l}\text { Observational } \\
\text { Study }\end{array}$ & $\begin{array}{l}\text { Investigate whether the increase in iron } \\
\text { within the cystic fibrosis lung } \\
\text { microenvironment has a role in } \\
\text { promoting bacterial replication or } \\
\text { whether it simply represents an } \\
\text { inflammatory state }\end{array}$ & $\begin{array}{l}\text { A direct relationship was found between sputum iron } \\
\text { and } P \text {. aeruginosagrowth in clinically stable patients, } \\
\text { but not in samples obtained during an acute } \\
\text { exacerbation }\end{array}$ \\
\hline $\begin{array}{l}\text { Nguyen } \\
\text { et al. } \\
\text { [23] }\end{array}$ & 2014 & In vitro study & $\begin{array}{l}\text { Understand the changes in iron } \\
\text { of the cystic fibrosis lung by } P \text {. } \\
\text { aeruginosa }\end{array}$ & $\begin{array}{l}\text { Pyoverdine production reduces with the disease's } \\
\text { progression, leading to the evolution of iron regulatory } \\
\text { pathways like the heme pathway, which maintains iron } \\
\text { homeostasis in the absence of this other iron uptake } \\
\text { system }\end{array}$ \\
\hline $\begin{array}{l}\text { Banin et } \\
\text { al. [24] }\end{array}$ & 2005 & In vitro study & $\begin{array}{l}\text { Examine the Impact of mutations In Iron } \\
\text { acquisition-signaling genes on biofilm } \\
\text { morphology }\end{array}$ & $\begin{array}{l}\text { P. aeruginosa acquires iron and supports normal biofilm } \\
\text { formation by using the siderophores pyoverdine or } \\
\text { pyochelin according to iron's availability. In the absence } \\
\text { of iron uptake, } P \text {. aeruginosa } 6 \text { rms atypical biofilms }\end{array}$ \\
\hline $\begin{array}{l}\text { Yang et } \\
\text { al. [28] }\end{array}$ & 2007 & In vitro study & $\begin{array}{l}\text { Provide information if the variation in } \\
\text { the availability of iron affects } P \text {. } \\
\text { aeruginosa DNA release and biofilm } \\
\text { formation }\end{array}$ & $\begin{array}{l}\text { Iron at low concentrations promotes } P \text {. aeruginosa } \\
\text { biofilm development via the up-regulation of the PQS } \\
\text { genes and the formation of extracellular DNA, and at } \\
\text { high levels suppresses biofilm development }\end{array}$ \\
\hline $\begin{array}{l}\text { Soldano } \\
\text { et al. } \\
\text { [33] }\end{array}$ & 2020 & In vitro study & $\begin{array}{l}\text { interaction in } P \text {. aeruginosa would } \\
\text { impair biofilm development }\end{array}$ & $\begin{array}{l}\text { Iron starvation conditions can be established } \\
\text { irrespective of the iron concentration in the environment } \\
\text { by blocking the BfrB-Bfd complex in P. aeruginosa, } \\
\text { which negatively affects biofilm formation }\end{array}$ \\
\hline Mettrick & & Observational & $\begin{array}{l}\text { Study the biofilm-inhibiting effects of } \\
\text { the hexadentate synthetic ferric iron } \\
\text { chelator, N, N'-bis (2-hydroxybenzyl) }\end{array}$ & HBED and colıstın, when used together, can inhibit \\
\hline
\end{tabular}




\section{Cureus}

\begin{tabular}{|c|c|c|c|c|}
\hline $\begin{array}{l}\text { et al. } \\
\text { [37] }\end{array}$ & 2020 & Study & $\begin{array}{l}\text { ethylenediamine-N, N'-diacetic acid } \\
\text { (HBED), on laboratory and clinical } \\
\text { strains of } P \text {. aeruginosa }\end{array}$ & $\begin{array}{l}\text { biofilm formation in both aerobic and anaerobic } \\
\text { conditions }\end{array}$ \\
\hline $\begin{array}{l}\text { Moreau- } \\
\text { Marquis } \\
\text { et al. } \\
{[38]}\end{array}$ & 2009 & In vitro study & $\begin{array}{l}\text { Investigate if iron chelators would } \\
\text { enhance tobacco use to treat cystic } \\
\text { fibrosis lung infections and eliminate } P \text {. } \\
\text { aeruginosa biofilms }\end{array}$ & $\begin{array}{l}\text { The use of the combination of tobramycin and iron } \\
\text { chelator drastically lowered the biomass of established } \\
\text { biofilms by } 90 \% \text { of the pre-treatment value }\end{array}$ \\
\hline $\begin{array}{l}\text { Aali et } \\
\text { al. [39] }\end{array}$ & 2017 & $\begin{array}{l}\text { Traditional } \\
\text { review }\end{array}$ & $\begin{array}{l}\text { Understand if the administration of iron } \\
\text { chelators to reduce the unregulated } \\
\text { ROS production by neutrophils could } \\
\text { serve as a novel treatment to improve } \\
\text { lung inflammation in cystic fibrosis } \\
\text { patients }\end{array}$ & $\begin{array}{l}\text { The inhalation route of administration of iron chelators is } \\
\text { the most appropriate as it lowers the chelators' } \\
\text { systemic effects by accumulating and acting locally in } \\
\text { the lungs }\end{array}$ \\
\hline $\begin{array}{l}\text { Kaneko } \\
\text { et al. } \\
\text { [43] }\end{array}$ & 2007 & In vitro study & $\begin{array}{l}\text { Investigate the use of gallium to disrupt } \\
\text { bacterial iron metabolism to inhibit } \\
\text { biofilm formation in } P \text {. aeruginosa }\end{array}$ & $\begin{array}{l}\text { Results showed that gallium inhibits } P \text {. aeruginosa. } \\
\text { growth and biofilm formation. It works by interrupting } \\
\text { iron metabolism }\end{array}$ \\
\hline $\begin{array}{l}\text { Zhanel } \\
\text { et al. } \\
\text { [44] }\end{array}$ & 2019 & $\begin{array}{l}\text { Traditional } \\
\text { review }\end{array}$ & $\begin{array}{l}\text { Review the existing published data for } \\
\text { cefiderocol in detail }\end{array}$ & $\begin{array}{l}\text { Cefiderocol acts against the Gram-negative bacilli by } \\
\text { inhibiting cell wall synthesis. Its ability to enter via active } \\
\text { iron transport systems has enabled it to overcome } \beta \text { - } \\
\text { lactam resistance associated with outer membrane } \\
\text { permeability mutations in } P \text {. aeruginosa }\end{array}$ \\
\hline
\end{tabular}

TABLE 3: Studies describing the novel therapeutics targeting iron

\section{Limitations}

Iron chelators demonstrated a very potent anti-biofilm effect in many studies. However, studies that investigated its efficacy were all conducted on laboratory strains of P.aeruginosa, which may be different from clinical strains. This is a concern as the clinical strain will respond differently to different iron chelators; hence, the combination of iron chelators may prove more effective clinically. The phase 1 clinical trial conducted with FDA-approved intravenous gallium was small, un-blinded, did not have control, and was limited to patients with mild cystic fibrosis lung disease; thus, the safety and effectiveness of gallium need to be established in future randomized studies with more advanced disease.

\section{Conclusions}

In this systematic review, we aimed to collect information on the significance of iron in chronic Pseudomonas infection and determine ways to address it. After thoroughly reviewing the studies, we found that iron played an integral role in helping $P$. aeruginos $a$ combat antibiotics by aiding in biofilm formation and it possesses multiple pathways to acquire iron, the most important being siderophores pyoverdine and pyochelin. Therefore, if the iron is targeted, we might be able to treat antibiotic-resistant Pseudomonas infection effectively. Many new therapeutic strategies have been developed over the years, the most promising being iron chelators, gallium, and cefiderocol to inhibit biofilm formation. Iron chelators such as deferoxamine, deferasirox, deferiprone, and IV gallium are FDA-approved and should be considered in future randomized clinical trials.

In our opinion, these new therapeutic approaches can increase survival rates in cystic fibrosis patients as the chronic bacterial infection is one of the most frequent causes of respiratory failure and mortality, and we hope our survey will encourage future clinical trials. These approaches can also be useful in infections caused by other resistant organisms thriving on iron, such as Escherichia coli and Staphylococcus aureus.

\section{Additional Information \\ Disclosures}

Conflicts of interest: In compliance with the ICMJE uniform disclosure form, all authors declare the following: Payment/services info: All authors have declared that no financial support was received from any organization for the submitted work. Financial relationships: All authors have declared that they have no financial relationships at present or within the previous three years with any organizations that might have an interest in the submitted work. Other relationships: All authors have declared that there are no other relationships or activities that could appear to have influenced the submitted work.

\section{References}


1. National Organization for Rare Disorders. (2017). Accessed: December 28, 2020: https://rarediseases.org/rare-diseases/cystic-fibrosis/.

2. Cystic Fibrosis Foundation: about cystic fibrosis. (2020). Accessed: December 28, 2020: https://www.cff.org/What-is-CF/About-Cystic-Fibrosis/.

3. Harrison F: Microbial ecology of the cystic fibrosis lung. Microbiology (Reading). 2007, 153:917-923. 10.1099/mic.0.2006/004077-0

4. Lyczak JB, Cannon CL, Pier GB: Lung infections associated with cystic fibrosis . Clin Microbiol Rev. 2002, 15:194-222. 10.1128/cmr.15.2.194-222.2002

5. Lipuma JJ: The changing microbial epidemiology in cystic fibrosis . Clin Microbiol Rev. 2010, 23:299-323. 10.1128/CMR.00068-09

6. Pang Z, Raudonis R, Glick BR, Lin TJ, Cheng Z: Antibiotic resistance in Pseudomonas aeruginosa: mechanisms and alternative therapeutic strategies. Biotechnol Adv. 2019, 37:177-192. 10.1016/j.biotechadv.2018.11.013

7. Drenkard E: Antimicrobial resistance of Pseudomonas aeruginosa biofilms . Microbes Infect. 2003, 5:12131219. 10.1016/j.micinf.2003.08.009

8. Høiby N, Ciofu O, Bjarnsholt T: Pseudomonas aeruginosa biofilms in cystic fibrosis . Future Microbiol. 2010, 5:1663-1674. 10.2217/fmb.10.125

9. Thi MTT, Wibowo D, Rehm BHA: Pseudomonas aeruginosa biofilms. Int J Mol Sci. 2020, 21:8671. 10.3390/ijms21228671

10. Bouvier NM: Cystic fibrosis and the war for iron at the host-pathogen battlefront . Proc Natl Acad Sci U S A. 2016, 113:1480-1482. 10.1073/pnas.1525101113

11. Hurley MN, Cámara M, Smyth AR: Novel approaches to the treatment of Pseudomonas aeruginosa infections in cystic fibrosis. Eur Respir J. 2012, 40:1014-1023. 10.1183/09031936.00042012

12. Moreau-Marquis S, Bomberger JM, Anderson GG, Swiatecka-Urban A, Ye S, O'Toole GA, Stanton BA: The DeltaF508-CFTR mutation results in increased biofilm formation by Pseudomonas aeruginosa by increasing iron availability. Am J Physiol Lung Cell Mol Physiol. 2008, 295:25-37. 10.1152/ajplung.00391.2007

13. Chhabra R, Saha A, Chamani A, Schneider N, Shah R, Nanjundan M: Iron pathways and iron chelation approaches in viral, microbial, and fungal infections. Pharmaceuticals (Basel). 2020, 13:275. 10.3390/ph13100275

14. Brown SA, Palmer KL, Whiteley M: Revisiting the host as a growth medium . Nat Rev Microbiol. 2008, 6:657666. 10.1038/nrmicro1955

15. Goss CH, Kaneko Y, Khuu L, et al.: Gallium disrupts bacterial iron metabolism and has therapeutic effects in mice and humans with lung infections. Sci Transl Med. 2018, 10:eaat7520. 10.1126/scitranslmed.aat7520

16. Moher D, Liberati A, Tetzlaff J, Altman DG; PRISMA Group: Preferred Reporting Items for Systematic Reviews and Meta-Analyses: The PRISMA Statement. PLoS Med. 2009, 6:e1000097. 10.1371/journal.pmed.1000097

17. Reid DW, Carroll V, O'May C, Champion A, Kirov SM: Increased airway iron as a potential factor in the persistence of Pseudomonas aeruginosa infection in cystic fibrosis. Eur Respir J. 2007, 30:286-292. 10.1183/09031936.00154006

18. Sunder-Plassmann G, Patruta SI, Hörl WH: Pathobiology of the role of iron in infection . Am J Kidney Dis. 1999, 34:S25-S29. 10.1053/AJKD034s00025

19. Vallyathan V, Mega JF, Shi X, Dalal NS: Enhanced generation of free radicals from phagocytes induced by mineral dusts. Am J Respir Cell Mol Biol. 1992, 6:404-413. 10.1165/ajrcmb/6.4.404

20. Hoepelman IM, Jaarsma EY, Verhoef J, Marx JJ: Polynuclear iron complexes impair the function of polymorphonuclear granulocytes. Br J Haematol. 1988, 68:385-389. 10.1111/j.1365-2141.1988.tb04219.x

21. Bullen JJ, Rogers HJ, Spalding PB, Ward CG: Iron and infection: the heart of the matter . FEMS Immunol Med Microbiol. 2005, 43:325-330. 10.1016/j.femsim.2004.11.010

22. Cornelis P, Dingemans J: Pseudomonas aeruginosa adapts its iron uptake strategies in function of the type of infections. Front Cell Infect Microbiol. 2013, 3:75. 10.3389/fcimb.2013.00075

23. Nguyen AT, O'Neill MJ, Watts AM, Robson CL, Lamont IL, Wilks A, Oglesby-Sherrouse AG: Adaptation of iron homeostasis pathways by a Pseudomonas aeruginosa pyoverdine mutant in the cystic fibrosis lung. J Bacteriol. 2014, 196:2265-2276. 10.1128/JB.01491-14

24. Banin E, Vasil ML, Greenberg EP: Iron and Pseudomonas aeruginosa biofilm formation . Proc Natl Acad Sci U S A. 2005, 102:11076-11081. 10.1073/pnas.0504266102

25. Breidenstein EB, de la Fuente-Núñez C, Hancock RE: Pseudomonas aeruginosa: all roads lead to resistance. Trends Microbiol. 2011, 19:419-426. 10.1016/j.tim.2011.04.005

26. Mulcahy LR, Burns JL, Lory S, Lewis K: Emergence of Pseudomonas aeruginosa strains producing high levels of persister cells in patients with cystic fibrosis. J Bacteriol. 2010, 192:6191-6199. 10.1128/JB.01651-09

27. Keren I, Kaldalu N, Spoering A, Wang Y, Lewis K: Persister cells and tolerance to antimicrobials . FEMS Microbiol Lett. 2004, 230:13-18. 10.1016/S0378-1097(03)00856-5

28. Yang L, Barken KB, Skindersoe ME, Christensen AB, Givskov M, Tolker-Nielsen T: Effects of iron on DNA release and biofilm development by Pseudomonas aeruginosa. Microbiology (Reading). 2007, 153:13181328. 10.1099/mic.0.2006/004911-0

29. Kidd TJ, Ramsay KA, Vidmar S, et al.: Pseudomonas aeruginosa genotypes acquired by children with cystic fibrosis by age 5-years. J Cyst Fibros. 2015, 14:361-369. 10.1016/j.jcf.2014.12.007

30. Emerson J, Rosenfeld M, McNamara S, Ramsey B, Gibson RL: Pseudomonas aeruginosa and other predictors of mortality and morbidity in young children with cystic fibrosis. Pediatr Pulmonol. 2002, 34:91-100. 10.1002/ppul.10127

31. Zar H, Saiman L, Quittell L, Prince A: Binding of Pseudomonas aeruginosa to respiratory epithelial cells from patients with various mutations in the cystic fibrosis transmembrane regulator. J Pediatr. 1995, 126:230-233. 10.1016/s0022-3476(95)70549-X

32. Pier GB, Grout M, Zaidi TS: Cystic fibrosis transmembrane conductance regulator is an epithelial cell receptor for clearance of Pseudomonas aeruginosa from the lung. Proc Natl Acad Sci U S A. 1997, 94:1208812093. 10.1073/pnas.94.22.12088 
33. Soldano A, Yao H, Chandler JR, Rivera M: Inhibiting iron mobilization from bacterioferritin in Pseudomonas aeruginosa impairs biofilm formation irrespective of environmental iron availability. ACS Infect Dis. 2020, 6:447-458. 10.1021/acsinfecdis.9b00398

34. Singh PK, Parsek MR, Greenberg EP, Welsh MJ: A component of innate immunity prevents bacterial biofilm development. Nature. 2002, 417:552-555. 10.1038/417552a

35. Jeong BC, Hawes C, Bonthrone KM, Macaskie LE: Iron acquisition from transferrin and lactoferrin by Pseudomonas aeruginosa pyoverdin. Microbiology (Reading). 1997, 143:2497-2507. 10.1099/00221287-1437-2509

36. Britigan BE, Hayek MB, Doebbeling BN, Fick RB Jr: Transferrin and lactoferrin undergo proteolytic cleavage in the Pseudomonas aeruginosa-infected lungs of patients with cystic fibrosis. Infect Immun. 1993, 61:5049-5055. 10.1128/IAI.61.12.5049-5055.1993

37. Mettrick K, Hassan K, Lamont I, Reid D: The iron-chelator, N,N'-bis (2-hydroxybenzyl) ethylenediamine$\mathrm{N}, \mathrm{N}$-diacetic acid is an effective colistin adjunct against clinical strains of biofilm-dwelling Pseudomonas aeruginosa. Antibiotics (Basel). 2020, 9:144. 10.3390/antibiotics9040144

38. Moreau-Marquis S, O'Toole GA, Stanton BA: Tobramycin and FDA-approved iron chelators eliminate Pseudomonas aeruginosa biofilms on cystic fibrosis cells. Am J Respir Cell Mol Biol. 2009, 41:305-313. 10.1165/rcmb.2008-02990C

39. Aali M, Caldwell A, House K, Zhou J, Chappe V, Lehmann C: Iron chelation as novel treatment for lung inflammation in cystic fibrosis. Med Hypotheses. 2017, 104:86-88. 10.1016/j.mehy.2017.05.029

40. Chitambar CR, Narasimhan J: Targeting iron-dependent DNA synthesis with gallium and transferringallium. Pathobiology. 1991, 59:3-10. 10.1159/000163609

41. Apseloff G: Therapeutic uses of gallium nitrate: past, present, and future . Am J Ther. 1999, 6:327-339. 10.1097/00045391-199911000-00008

42. Vasil ML, Ochsner UA: The response of Pseudomonas aeruginosa to iron: genetics, biochemistry and virulence. Mol Microbiol. 1999, 34:399-413. 10.1046/j.1365-2958.1999.01586.x

43. Kaneko Y, Thoendel M, Olakanmi O, Britigan BE, Singh PK: The transition metal gallium disrupts Pseudomonas aeruginosa iron metabolism and has antimicrobial and antibiofilm activity. J Clin Invest. 2007, 117:877-888. 10.1172/JCI30783

44. Zhanel GG, Golden AR, Zelenitsky S, et al.: Cefiderocol: a siderophore cephalosporin with activity against carbapenem-resistant and multidrug-resistant Gram-negative bacilli. Drugs. 2019, 79:271-289. 10.1007/s40265-019-1055-2 